\title{
Effects of the Bull on Conception Rate of Dairy Cows in Different Seasons and According to AI Type
}

\author{
Gabriela Bueno Luz ${ }^{1,3}$, Andressa Stein Maffi, ${ }^{1,3}$, Lucas Balinhas Farias ${ }^{1,3}$, \\ Eduardo Goulart Xavier², Márcio Erpen Lima ${ }^{3}$, Marcio Nunes Corrêa ${ }^{3}$ \& Cássio Cassal Brauner ${ }^{1,3}$
}

\begin{abstract}
Background: Reproductive efficiency is one of the most important factors affecting the performance dairy cattle, and fixedtime artificial insemination (TAI) is an important biotechnology factor employed in bovine livestock. The achievement of satisfactory results in TAI protocols depends of several factors, such as health and body condition, milk yield, environmental temperatures, ovulation time, semen manipulation, as well as semen quality. The goal of this study was to evaluate the conception rate of heifers and multiparous cows based on different Holstein bulls used for artificial insemination (AI). The effects of the type of management AI, animal category, and season of the year were also examined.

Materials, Methods \& Results: A three-year database on the reproductive management of a dairy farm was formed. All the cows and heifers were of the Holstein breed, in semi-intensive nutritional management, milked twice a day, and received a total mix ration. After 45 days in milk, when cows were observed twice daily with estrus signs, posterior artificial insemination occurred $12 \mathrm{~h}$ after estrus visualization was made. However, cows that were not observed in estrus were submitted to a timed artificial insemination (TAI). In this study, these fixed factors were considered: bulls utilized for the AI (totalizing 10 animals with at least 100 inseminations in each season, denoted by the letter B and a number - B1, B2, B3, B4, B5, B6, B7, B8, B9, B10); the season of the insemination (spring/summer being from November to April and autumn/winter from May to October), category animal (heifers, animals that never have been calved, or multiparous, animals that have already given birth more than once), and the type of AI (which included TAI using a protocol for synchronization, but cows having not necessarily shown estrus signs at the AI; ETAI: using protocol of synchronization, cows showing estrus signs at the AI; and AI with estrus visualization, without protocol of synchronization when animals were observed in estrus and were inseminated $12 \mathrm{~h}$ later. The fertility parameter of the bulls and reproductive performance in AI was based on conception rate. There was a statistical difference among different bulls in the same season $(P \leq 0.05)$. There was also a difference in reproductive performance of the same bulls between seasons, autumn/winter and spring/summer; B8 37.8\% vs. $32.0 \%$ $(P=0.05)$ and $\mathrm{B} 1035.1 \%$ vs. $20.7 \%(P=0.003)$. Regarding the individual animal category, only one bull (B6) demonstrated higher reproductive performance when utilized in the AI of heifers than multiparous $39.2 \%$ vs. $27.2 \%(P=0.01)$. Similarly, regarding the effect of the type of AI, only one bull (B8) exhibited different results, obtaining better results for conception rate when utilized in fixed TAI with estrus visualization (35.5\%) and in the AI with estrus visualization (39.0\%) compared with that of TAI [19.9\%] $(P<0.05)$.

Discussion: From these results, it was observed that some bulls exhibited better performance in situations of greater challenge. In addition, some animals presented variation in efficiency with the demonstration of estrus or not. Therefore, bulls that present semen with higher fertility in certain types of AI could be utilized on a larger scale for to increase the reproductive rates in artificial insemination. The results of this study indicate that despite the tests indicating the semen that is submitted is adequate, there are still variations in quality and the reproductive efficiency of each bull. With the effects varying based on fertility and on different environmental and management situations.
\end{abstract}

Keywords: dairy cattle, estrus visualization, fertility, fixed-time artificial insemination, reproductive management. 


\section{INTRODUCTION}

The reproductive efficiency is one of the most important factors affecting the performance and profitability of dairy cattle [3]. Fixed-timed artificial insemination (TAI) is an important biotechnology factor employed in cattle [7], which is used for improvement and genetic advances [8].

The achievement of satisfactory results in TAI protocols depends of several factors, such as health and body condition, milk yield, environmental temperatures, insemination time in relation to ovulation time, semen manipulation and placing, as well as semen quality [12-14].

Temperature is an important environmental factor that has a substantial effect on reproductive results, particularly in high producing dairy cows, which are extremely sensitive to climatic conditions $[5,9]$. In addition, the physiological functions within the dairy cow are quite complex, and it is known that bulls also have a fundamental and determinant role in conception rate. Semen utilized in artificial insemination is provided by specialized companies; however, even proven bulls showing satisfactory reports in seminal quality, some factors remain to be evaluated. Therefore, these unknown effects could potentially interfere with the results of conception.

Because of individual variation in the bull and the semen used, there are potential limitations based on season (autumn/winter or spring/summer), and also the productivity capacity of the herd. The goal of this study was to evaluate conception rate of heifers and multiparous cows based on different Holstein bulls used in artificial insemination, and also related with the type of AI, animal category (heifers or multiparous), and season of the year.

\section{MATERIALS AND METHODS}

\section{Experimental design}

The data for this study were obtained retrospectively from a reproductive database of 9488 inseminations of dairy cows and heifers mated with 10 bulls, in a dairy farm with 800 cows in milk, localized in Rio Grande - RS (Brazil) coordinates $32^{\circ} 16 \mathrm{~S}, 52^{\circ} 32 \mathrm{~W}$. This includes information for inseminations conducted during 2012-2014.

All the cows and heifers were of the Holstein breed, in semi-intensive nutritional management, milked twice a day, and received a total mix ration. After 45 days in milk, when cows were observed twice daily with estrus signs, posterior artificial insemination occurred $12 \mathrm{~h}$ after estrus visualization was made. However, cows that were not observed in estrus were submitted to a TAI.

\section{TAI protocol}

During the TAI protocol, on day 0, the animals received $2 \mathrm{mg}$ of estradiol benzoate (Gonadiol $\left.{ }^{\circledR}, \mathrm{im}\right) 1$ and a vaginal device containing $1.9 \mathrm{~g}$ of progesterone $\left(\mathrm{CIDR}^{\circledR}\right)^{1}$. On day 7 , the devices were removed, and $5 \mathrm{mg}$ of dinoprost (Lutalyse $\left.{ }^{\circledR}\right)^{1}$ was administered. On day $8,0.5 \mathrm{mg}$ of estradiol cypionate $\left(\text { E.C.P }{ }^{\circledR}\right)^{1}$ was administered, and on day 10 the AI was performed whether estrus was detected or not. Pregnancy status was determined by ultrasonography at 28 to $35 \mathrm{~d}$ after AI. Examinations with and ultrasound (5-0-MHz, Weld 3000, B-mode) ${ }^{2}$ and transrectal linear probe were performed for the diagnosis of pregnancy at 30 days after artificial insemination.

\section{Artificial insemination}

In this study, these fixed factors were considered: bulls utilized for the AI (totalizing 10 animals with at least 100 inseminations in each season); the season of the insemination (spring/summer being from November to April and autumn/winter from May to October), category animal (heifers, animals that never have been calved, or multiparous, animals that have already given birth more than once), and the type of AI, which included TAI (using a protocol for synchronization, but cows having not necessarily shown estrus signs at the AI); ETAI (using protocol of synchronization, cows showing estrus signs at the $\mathrm{AI}$ ), and $\mathrm{AI}$ with estrus visualization, without protocol of synchronization (when animals were observed in estrus and were inseminated $12 \mathrm{~h}$ later). The semen were provided from specialized centrals, and mating was previously professionally conducted to improve the genetic and phenotypic characteristics. As a criterion of inclusion, only bulls that presented at least $100 \mathrm{AI}$ in each variable evaluated, and were denoted in this study by the letter B and a number (B1, B2, B3, B4, B5, B6, $\mathrm{B} 7, \mathrm{~B} 8, \mathrm{~B} 9, \mathrm{~B} 10)$ for identification in the results without exposing the commercial name.

\section{Statistical analysis}

Statistical analysis was performed using the program NCSS 2005. The data were analyzed using the cross tabulation and/or chi-square tests for percentage of conception, considering significant results those with probability values equal or less than 0.05 . 


\section{RESULTS}

In this study, the fertility parameter for the bulls, and the reproductive performance in the TAI, was based on conception rate. Different bulls in the same season were compared, and under same conditions of presence or absence of estrus at the time of AI. Furthermore, the performance of the same bull in relation to different factors (season, estrus presentation) was evaluated.

Table 1 shows the bulls' performance throughout the seasons. It can be observed for the season, in the spring/summer, some animals stood out, showing a good performance despite other adverse conditions. Regarding autumn/winter, when the environmental conditions were more favorable to reproduction, the performance was similar among the animals. Furthermore, some animals (B8 and B10) exhibited differences in their performance between the two seasons, having better results in autumn/winter.

For spring/summer, the conception rate for bulls B8 and B9, 32.0\% and 36.8\%, respectively, exhibited better performance (greater percentages) than bulls B2 (20.5\%), B5 (27.4\%), B7 (16.8\%), and B10 (20.7\%).
Regarding the reproductive performance of the same bull across seasons, only two bulls, of the six utilized with multiple seasons (autumn/winter and spring/summer), exhibited a significant difference. B8 exhibited $37.8 \%$ and $32.0 \%(P=0.05)$ and $\mathrm{B} 10$ was successful $35.1 \%$ and $20.7 \%(P=0.003)$ in autumn/ winter and spring/summer, respectively.

Comparing the effect of the bull in the TAI of heifers and multiparous females with high yield (Table 2), no significant difference among categories was detected; however, when the effect between the categories (heifers vs. multiparous) was analyzed, B6 exhibited better performance when utilized in the AI of heifers than in multiparous cows $(P=0.01)$, with $39.2 \%$ vs. $27.2 \%$, respectively.

Regarding the type of AI, TAI, ETAI, or AI with observed estrous, no differences between the bulls utilized were detected (Table 3) However, when comparing the same bull in different types of AI, only B8 presented significant differences in reproductive performance, being lower when utilized in the TAI relative to that of ETAI and AI with estrous observed $(P=0.000013)$.

Table 1. Conception rate following AI with a comparison of bulls in the same and different seasons.

\begin{tabular}{cccc}
\hline Bull & Spring/Summer & Autumn/Winter & $P$ (between seasons) \\
\hline B1 & $30.3(46 / 162)^{\mathrm{abcA}}$ & $31.6(80 / 253)^{\mathrm{aA}}$ & 0.77 \\
B2 & $20.5(38 / 185)^{\mathrm{bc}}$ & - & \\
B3 & - & $41.5(103 / 248)^{\mathrm{a}}$ & \\
B4 & $30.3(69 / 228)^{\mathrm{abc}}$ & - & 0.06 \\
B5 & $27.4(120 / 460)^{\mathrm{bcA}}$ & $33.1(140 / 243)^{\mathrm{aA}}$ & 0.70 \\
B6 & $34.3(46 / 134)^{\mathrm{Aa}}$ & $32.6(173 / 531)^{\mathrm{aA}}$ & 0.05 \\
B7 & $16.8(28 / 167)^{\mathrm{bc}}$ & - & 0.84 \\
B8 & $32.0(198 / 618)^{\mathrm{aA}}$ & $37.8(168 / 445)^{\mathrm{aA}}$ & 0.003 \\
B9 & $36.8(148 / 402)^{\mathrm{aA}}$ & $37.6(67 / 178)^{\mathrm{aA}}$ & $<0.001$ \\
B10 & $20.7(50 / 242)^{\mathrm{bcB}}$ & $35.1(40 / 114)^{\mathrm{aA}}$ & \\
Overall & $28.59(743 / 2598)$ & $38.32(771 / 2012)$ & \\
\hline
\end{tabular}

Means followed by different lowercase letter a,b,c indicate differences between rows (Bulls), at $P<0.05$ using the chi-square test. Means followed by different capital letters ${ }^{\mathrm{A}, \mathrm{B}}$ indicate differences between columns (Spring/Summer Autumn/Winter), at $P<0.05$ using the chi-square test.

Table 2. Conception rate comparing different bulls in the AI of heifers and multiparous females with high yield.

\begin{tabular}{cccc}
\hline Bull & Heifers & Multiparous & $P$ (heifers vs. multiparous) \\
\hline B1 & - & $31.4(61 / 194)^{\mathrm{a}}$ & \\
B2 & - & $22.6(26 / 115)^{\mathrm{a}}$ & \\
B3 & - & - & \\
B4 & - & $28.8(42 / 146)^{\mathrm{a}}$ & 0.39 \\
B5 & $32.5(95 / 292)^{\mathrm{aA}}$ & $29.4(100 / 340)^{\mathrm{aB}}$ & 0.01 \\
B6 & $39.2(60 / 153)^{\mathrm{aA}}$ & $27.2(76 / 279)^{\mathrm{aB}}$ & 0.09 \\
B7 & - & - & 0.32 \\
B8 & $36,8(100 / 272)^{\mathrm{aA}}$ & $30,8(151 / 491)^{\mathrm{aA}}$ & $<0.001$ \\
B9 & $40(78 / 195)^{\mathrm{aA}}$ & $35.2(74 / 210)^{\mathrm{aA}}$ & \\
B10 & - & $23.5(31 / 132)^{\mathrm{a}}$ & \\
Overall & $36.51(333 / 912)$ & $29.41(561 / 1907)$ & \\
\hline
\end{tabular}


G.B. Luz, A.S. Maffi, L.B. Farias, et al. 2018. Effects of the Bull on Conception Rate of Dairy Cows in Different Seasons and According to Al Type.

Acta Scientiae Veterinariae. 46: 1552.

Table 3. Conception rate comparison for different bulls and types of AI.

\begin{tabular}{ccccc}
\hline Bull & TAI & ETAI & AI observed & $P$ (types of AI) \\
\hline B1 & - & - & $35.4(40 / 113)^{\mathrm{a}}$ & \\
B3 & - & - & $41.5(44 / 106)^{\mathrm{a}}$ & \\
B4 & - & - & - & \\
B5 & $25.5(39 / 153)^{\mathrm{Aa}}$ & $34.2(65 / 190)^{\mathrm{aA}}$ & $31.5(91 / 289)^{\mathrm{aA}}$ & 0.21 \\
B6 & & $41.7(58 / 139)^{\mathrm{aA}}$ & $32.0(63 / 197)^{\mathrm{aA}}$ & 0.06 \\
B8 & $19.9(41 / 206)^{\mathrm{Ab}}$ & $35.5(75 / 211)^{\mathrm{aA}}$ & $39.0(135 / 346)^{\mathrm{aA}}$ & 0.000013 \\
B9 & - & $45.1(55 / 122)^{\mathrm{aA}}$ & $38.3(74 / 193)^{\mathrm{aA}}$ & 0.23 \\
\hline
\end{tabular}

Means followed by different lowercase letters a,b,c indicate differences between rows (Bulls), at $P<0.05$ using the chi-square test. Means followed by different capital letters ${ }^{\mathrm{A}, \mathrm{B}}$ indicate differences between columns (Type of $\mathrm{AI}$ ), at $P<0.05$ using the chi-square test.

\section{DISCUSSION}

In this study, the fertility parameters of the bulls and the reproductive performance with TAI, was considered based on conception rate. The results showed differences in bulls within the same season, and with the presence or absence of estrus at the time of AI. Furthermore, beyond what was evaluated is the performance of the same bull in relation to different situations (season, estrus presentation).

As can be observed in the results, season had an effect on the reproductive performance of the bulls. In particular, comparison in the same season revealed large difference in conception rate, where the bull with lesser performance exhibited 16.5\% (B7) and the bull with better performance exhibited (36.8\%), demonstrating that despite having been utilized with females under the same management conditions, the effect of fertility of the bull was a determinant factor for better results in TAI during the same season. As in this study, another study in 2015 [14] evaluating 4 different bulls, reported differences of up to $15.6 \%$ between the bulls in the conception rate of the cows.

Seasonal variation also occurred and could reduce the conception rate, because of the semen of the bull utilized or the female inseminated, which are exposed and susceptible to thermal stress and adverse environmental conditions, as seen in the comparison of the same bulls in different seasons (autumn/winter or spring/summer) in this study. Only two bulls showed an effect. B8 and B10 had better reproductive performance in autumn/winter than in spring/summer: $37.8 \%$ vs. $32.0 \%$ (B8, autumn/winter vs. spring/summer) $[P=$ 0.05 )] and $35.1 \%$ vs. $20.7 \%$ (B10, autumn/winter vs. spring/summer) $[P=0.003]$. Thus, one could speculate there is variation in the seminal quality between the seasons, demonstrating the susceptibility of individuals to seasonal thermal stress.
The hotter months of the year are usually the months with lower reproductive performance; factors related to thermal stress reduce the fertility in dairy herds [9]. This effect occurs mainly because of thermal stress, and the probability that the insemination results in a viable embryo decreases as the body temperature increases. The oocytes, the spermatozoids, and the embryo are unable to maintain normal functions when submitted to high temperatures, and thus, the pregnancy is interrupted when these cells are exposed to maternal hyperthermia [4].

In a recent study evaluating seasonal variation in semen quality of different bulls [6], through the use of computer-assisted sperm analysis and flow cytometry to detect seasonal variations, the effect of thermal stress in the summer on spermatic quality after frozen was variable between the bulls. That is, not all bulls exhibited seasonal alterations in their functional spermatic parameters.

When the effect of the bull was evaluated with the variable animal category, i.e., heifers and multiparous cows with high milk yield, one bull (B6) exhibited a difference between the categories, exhibiting a higher conception rate in heifers, $39.2 \%(P=0.01)$. In this case, when analyzing the conception rate of heifers vs. multiparous cows, it is not just the influence of the bull that is examined, but also the physiological status and the endocrine challenge to which the cow (multiparous) was submitted. Cows in lactation have inferior reproductive performance, and conception rate is lower in the trait associated with the genetic selection of this animal for high milk yield, whereas the fertility of Holstein heifers remains relatively stable and markedly higher than that of cows in lactation. Associated with this, it is suggested that the low fertility of cows in lactation of high milk yield, may be the result of possible differences in the oocyte quality and the levels of follicular steroids $[1,11]$. 
In the farm where the animals in this research were utilized, three types of AI, depending the case, were used. Thus, the effect of the bull on the AI variable was evaluated: ETAI, TAI, or just AI with estrus detection, without synchronization protocol. An attempt to identify bulls with better performance in a given AI method or situation was made; however, only one bull (B8) exhibited a difference in the type of AI, being better in the ETAI and the AI with estrus detection $(P$ $=0.000013)$. Perhaps this parameter is not a limiting factor for the performance reproductive bulls.

The set of interactions between ovulation of the female, fertility of the spermatozoids, and the viable time of the oocyte in the female genital tract after ovulation becomes extremely decisive and dependent on the ideal moment of insemination [2]. Thus, the spermatozoid being considered qualitatively viable and potentially fertile, it is necessary that it has morphology, metabolic activity, and normal membranes. The pre-requisites for the events related to the process of fertilization are: spermatic capacitation, penetration into oocyte coatings, connection to the zona pellucida, and melting with the oolemma may occur $[10,15]$. Therefore, bulls that present semen with higher fertility in certain types of AI could be utilized on a larger scale for to increase the reproductive rates in artificial insemination.

The implantation of artificial insemination into the productive system, is a biotechnology of high applicability, favoring genetical enhancement of the herd. Thus, more studies are needed to investigate the possible variables that could interfere with the results. It is worth mentioning that most of the research conducted up to now was related to the effects of the bull in TAI programs for beef cattle. The results of this study indicate that despite the tests indicating the semen that is submitted is adequate, there are still variations in quality and the reproductive efficiency of each bull. With the effects varying based on fertility and on different environmental and management situations.

\section{CONCLUSIONS}

The period of the year, the animal category, and the type of AI used interfered with the reproductive performance of Holstein bulls based on conception rate of heifers and multiparous cows under the same management conditions.

\section{MANUFACTURERS}

'Zoetis Saúde Animal. São Paulo, SP, Brazil.

${ }^{2}$ Well.d Medical Electronics Company Ltd. Shenzhen, China.

Acknowledgments. To the Núcleo de Pesquisa, Ensino e Extensão em Pecuária (NUPEEC) and Granjas 4 Irmãos S.A. for providing the database.

Declaration of interest. The authors report no conflicts of interest. The authors are responsible for the content and writing of the paper.

\section{REFERENCES}

1 Arav A. \& Zvi R. 2008. Do chilling injury and heat stress share the same mechanism of injury in oocytes? Molecular and Cellular Endocrinology. 282(1): 150-152.

2 Gosálvez J., Ramirez M.A., López-Fernández C., Crespo F., Evans K.M., Kjelland M.E. \& Moreno J.F. 2011. Sex-sorted bovine spermatozoa and DNA damage: II. Dynamic features. Theriogenology. 75(2): 206-211.

3 Gröhn Y.T. \& Rajala-Schultz P.J. 2000. Epidemiology of reproductive performance in dairy cows. Animal Reproduction Science. 60(2): 605-614.

4 Hansen P.J. \& Aréchiga C.F. 1994. Reducing effects of heat stress on reproduction of dairy cow. In: International Conference on Livestock in the Tropics (Gainesville, USA). pp.92-99.

5 Hansen P.J., Drost M., Rivera R.M., Paula-Lopes F.F., Al-Katanani Y.M., Krininger C.E. \& Chase C.C. 2001. Adverse impact of heat stress on embryo production: causes and strategies for mitigation. Theriogenology. 55(1): 91103.

6 Malama E., Zeron Y., Janett F., Siuda M., Roth Z. \& Bollwein H. 2017. Use of computer-assisted sperm analysis and flow cytometry to detect seasonal variations of bovine semen quality. Theriogenology. 87(1): 79-90.

7 Pursley J. R., Mee M.O. \& Wiltbank M.C. 1995. Synchronization of ovulation in dairy cows using PGF2 $\alpha$ and GnRH. Theriogenology. 44(7): 915-923.

8 Pursley J.R., Wiltbank M.C., Stevenson J.S., Ottobre J.S., Garverick H.A. \& Anderson L.L. 1997. Pregnancy rates per artificial insemination for cows and heifers inseminated at a synchronized ovulation or synchronized estrus. Journal of Dairy Science. 80(2): 295-300. 
9 De Rensis F. \& Scaramuzzi R.J. 2003. Heat stress and seasonal effects on reproduction in the dairy cow - a review. Theriogenology. 60(6): 1139-1151.

10 Rodriguez-Martinez H., Zhang B.R. \& Larsson B. 1997. Bovine semen quality and the ability to produce embryos in vivo and in vitro. Arquivos da Faculdade de Veterinária da UFRGS. 25(1): 108-126.

11 Roth Z. 2008. Heat stress, the follicle, and its enclosed oocyte: mechanisms and potential strategies to improve fertility in dairy cows. Reproduction in Domestic Animals. 43(2): 238-244.

12 Santos J.E.P. 2000. Importância da alimentação na reprodução da fêmea bovina. In: Workshop sobre reprodução animal. v.1. Pelotas: EMBRAPA, pp.7-82.

13 Santos R., Vasconcelos J., Meneghetti M., Silva E. \& Wechsler F. 2003. Efeito da ovulação à primeira aplicação de GnRH em protocolos de inseminação artificial em tempo fixo nas taxas de sincronização e prenhez em vacas de leite em lactação. Revista Brasileira de Reprodução Animal. 27(3): 437-438.

14 Silva C.B., Rodriguez M.A.P., Azevedo Junior J., Santos B.V.B., Dias K.J.P., Costa M.D. \& Ruas J.R.M. 2015. Efeito do touro sobre a ocorrência de prenhez de fêmeas submetidas à IATF Fórum de ensino pesquisa extensão e Gestão. In: $9^{\circ}$ Fórum de Ensino, Pesquisa, Extensão e Gestão (Montes Claros, Brasil). p.202.

15 Yanagimachi R. 1994. Mammalian fertilization. In: Knobil E. \& Neill J.D. (Eds). The Physiology of Reproduction. 2nd edn. New York: Raven, pp.189-317. 